\title{
Surgical Treatment of Tetralogy of Fallot with Pulmonary Valve Agenesis in a 22 Years Old Patient
}

\author{
Papa Salmane Ba, Kabulo Yannick, Momar Sokhna Diop, Papa Amath Diagne, \\ Ndeye Fatou Sow, Papa Adama Dieng, Amadou Gabriel Ciss \\ Thoracic and Cardiovascular Surgery Department, CHU Fann, Dakar, Senegal \\ Email: mansalb@yahoo.fr
}

How to cite this paper: Ba, P.S., Yannick, K., Diop, M.S., Diagne, P.A., Sow, N.F., Dieng, P.A. and Ciss, A.G. (2021) Surgical Treatment of Tetralogy of Fallot with Pulmonary Valve Agenesis in a 22 Years Old Patient. World Journal of Cardiovascular Surgery, 11, 29-36.

https://doi.org/10.4236/wjcs.2021.114005

Received: December 9, 2020

Accepted: April 12, 2021

Published: April 15, 2021

Copyright $\odot 2021$ by author(s) and Scientific Research Publishing Inc. This work is licensed under the Creative Commons Attribution International License (CC BY 4.0).

http://creativecommons.org/licenses/by/4.0/

\begin{abstract}
Agenesis of pulmonary valve is a rare variant and severe form of Tetralogy of Fallot (ToF). The evolution is usually marked by respiratory and cardiac failure at early age, which needs early surgical correction. Uncorrected treatment of Tetralogy of Fallot diagnosed at adult age is infrequent and only few studies have been described. We present here a rare case of a 22 years old patient who presented with dyspnea since childhood. Subsequent investigations allowed diagnosis of treatment of Tetralogy of Fallot with agenesis of the pulmonary valve. Following the assessment, the patient underwent a surgical repair and the recovery was uneventful. The management of treatment of Tetralogy of Fallot with pulmonary valve agenesis in adult period remains complex, requiring different surgical techniques.
\end{abstract}

\section{Keywords}

Tetralogy of Fallot, Pulmonary Valve Agenesis, Adult, Surgical Repair

\section{Introduction}

Pulmonary valve agenesis with ventricular septal defect is a rare variant of Tetralogy of Fallot. It occurs in 3\% to 6\% of Tetralogies of Fallot (ToF) [1]. Absent pulmonary valve syndrome is an uncommon variant of Tetralogy of Fallot, which manifests itself morphologically as vestigial pulmonary valve cusps at the right ventricle-pulmonary trunk junction, significant pulmonary regurgitation and aneurysmal dilatation of the proximal and mediastinal arteries, the aneurysmal dilated pulmonary arteries may compress the tracheobronchial tree and cause severe respiratory distress in the neonatal or infant period. Early surgical 
correction in these patients is necessary despite the high operative mortality rate. The goal of surgical repair is to correct ToF and relieve the central air way compression [2]. The treatment of patients with the syndrome of Tetralogy of Fallot with absent or rudimentary pulmonary valve should be individualized on the basis of the patient's age and symptoms. For those rare patients who survive beyond infancy, elective repair can be done before the onset of hemodynamic deterioration or respiratory complications associated with the progressive dilatation of the central pulmonary arterial system [3]. There is currently no literature emanating from Africa that has been published on Tetralogy of Fallot with absent pulmonary valve syndrome [4]. Therefore, we present a case of Tetralogy of Fallot with pulmonary valve agenesis in an adult who underwent surgical repair in a Sub African center.

\section{Case Report}

A 22-year-old patient presented with history of stable NYHA stage II dyspnea since the age of 6 months. On admission to our cardiac surgery department, clinical examination found a BMI of $14.17 \mathrm{~kg} / \mathrm{m}^{2}$. He had mucosal and conjunctival hyperemia without cyanosis nor finger clubbing. He had an oxygen saturation of $97 \%$ in room air. Cardiovascular examination revealed a grade 3/6 diastolic murmur at the left border of the sternum and a grade $4 / 6$ mesocardiac systolic murmur. The electrocardiogram showed a regular sinus rhythm with right atrial hypertrophy, right ventricular hypertrophy and an incomplete right bundle branch block. Chest X-rays showed cardiomegaly with a cardiothoracic ratio of 0.63 and enlarged pulmonary arteries. Transthoracic echocardiography showed pulmonary valve agenesis with significant pulmonary regurgitation, a wide subaortic ventricular septal defect with a 50\% dextroposed aorta, infundibular stenosis (33 mmHg peak gradient) with significant dilatation of the 2 pulmonary branches. The trunk of the pulmonary artery measured $30 \mathrm{~mm}$.

Thoracic computed tomography (Figure 1) showed pulmonary valve agenesis with proximal trunk stenosis of a pulmonary artery measuring $10 \mathrm{~mm}$ in the first portion, trunk aneurysmal dilatation in the second portion and dilatation of the pulmonary branches $(35 \mathrm{~mm}$ for the right and $28 \mathrm{~mm}$ for the left). The aortic arch was in the right side. No sign of bronchial compression was seen.

Surgery was indicated and was done for this patient. After a median sternotomy, intraoperative exploration, under cardiopulmonary bypass with bicaval cannulation and moderate hypothermia, showed dilatation of the right heart chambers which was thick. The pulmonary artery trunk and its branches were dilated without major aneurysm. The absence of pulmonary valve was noted (Figure 2). A significant infundibular stenosis and a sub-aortic $14 \mathrm{~mm}$ wide large ventricular septal defect were founded.

We carried out an extensive infundibular fibromuscular resection through the right atrium at first. The ventricular septal defect was closed by a bovine pericardial patch with continuous purse string. A small infundibulotomy was done. 
The infundibulotomy was extended by a transannular incision up to the pulmonary bifurcation. Residual muscles were resected to widen the infundibulum.

A biological valve (Biomedica $n^{\circ} 23$ of bovine pericardium) was inserted in the remaing pulmonary annular with continuous suture using polypropylene 4/0 (Figure 3). It was covered by bovine pericardial hood (Figure 4) recovering the anterior portion of the valve. A small atrial septal defect of $4 \mathrm{~mm}$ was created and left.

The patient was weaned from bypass. Postoperative transesophageal ultrasound showed a well fitted patch covering the ventricular septal defect and a pulmonary prosthesis in place with RV-PA gradient (Right Ventricular-Pulmonary Artery gradient) at $16 \mathrm{mmHg}$. Protamine was given and sternum was closed. The length of stay in intensive care unit was 3 days, followed by 8 days in the hospital ward. The post-operative period was marked by mild pericardial circumferential effusion, which evolved well after 2 weeks of follow-up. The outcome after surgery was good with improvement in symptoms. The follow-up ultrasound performed two months after surgical correction showed a right midventricular stenosis (Peak Gradient: $55 \mathrm{mmHg}$ ), a dilated pulmonary artery with a small pulmonary valve.
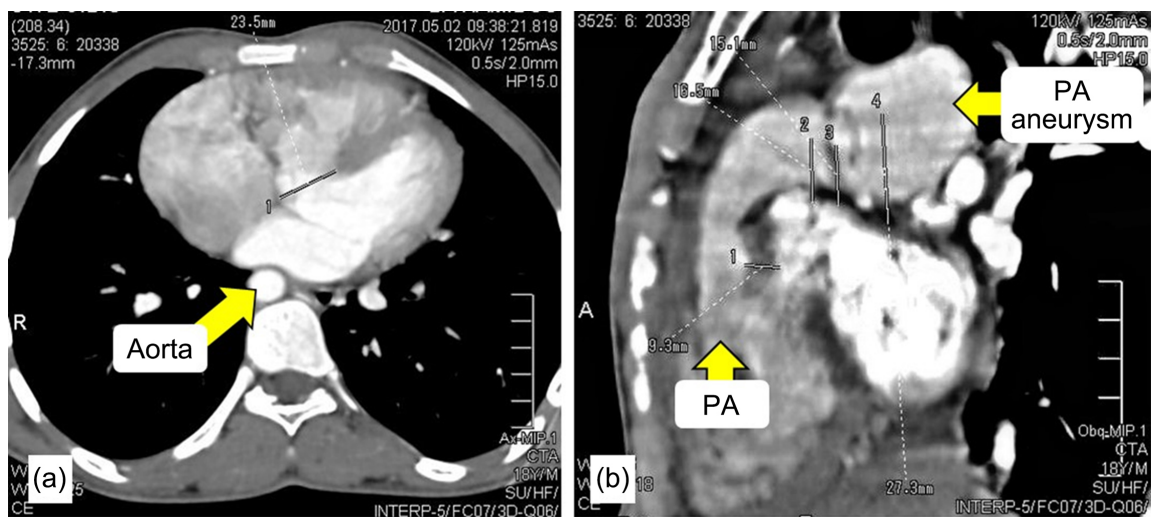

Figure 1. Chest CT angiography shows: (a) Aorta in the right side (b) Pulmonary valve agenesis with proximal trunk stenosis of a pulmonary artery measuring $10 \mathrm{~mm}$, trunk aneurysmal dilatation.

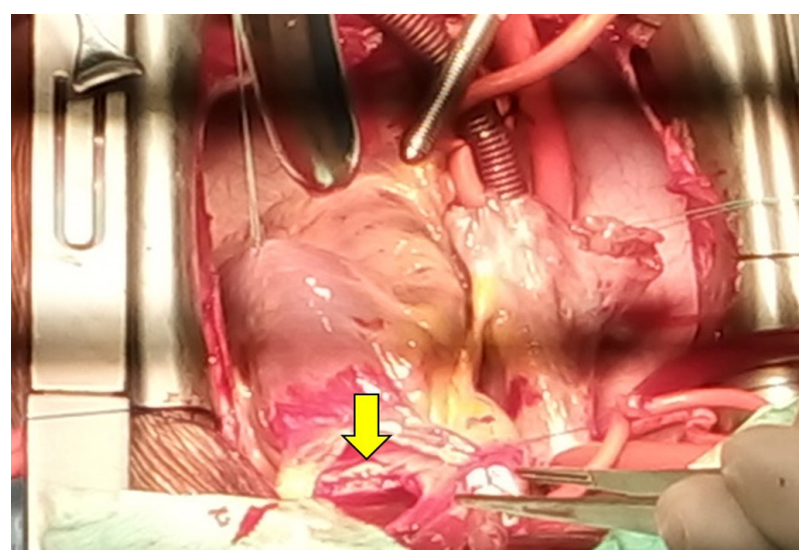

Figure 2. Operative view showing the absence of pulmonary valves (Arrow). 


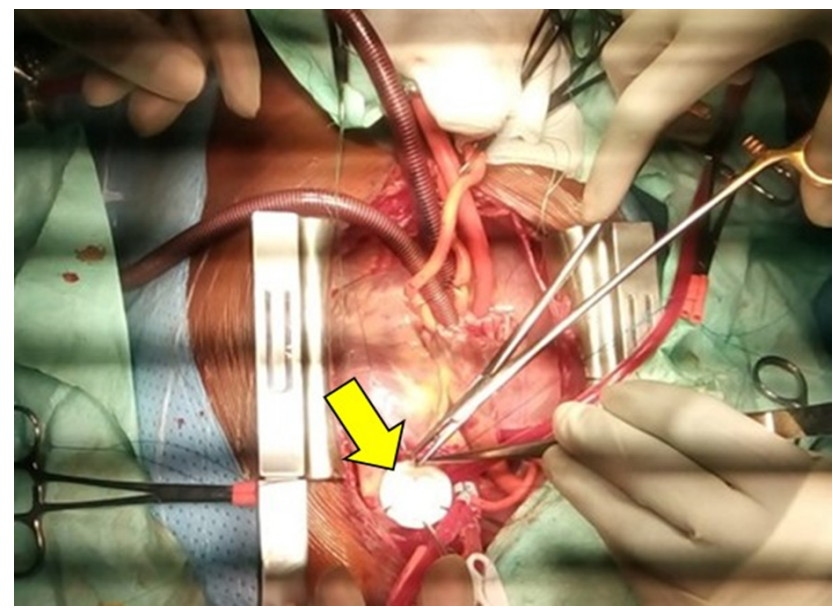

Figure 3. Operative view: placement of bioprosthesis (Arrow).

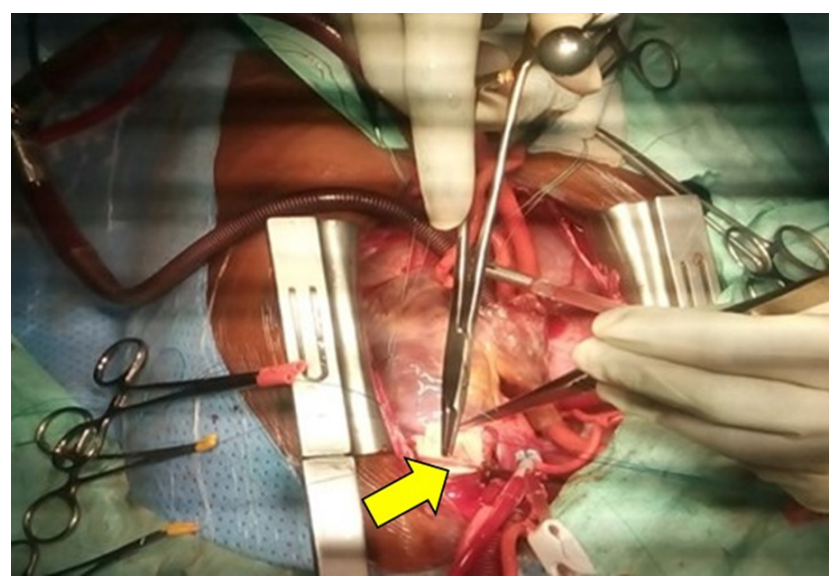

Figure 4. Operative view: placement of a transannular hood patch on the trunk of the pulmonary artery (Arrow).

\section{Discussion}

The diagnosis of Tetralogy of Fallot with agenesis of the pulmonary valve in adulthood is rare. Most of these patients do not survive without surgery and the average age of surgical repair is 9 months to 1.4 years [5]. The absence of the pulmonary valve causes to-and-fro flow between the right ventricle and the PAs, which leads to severe dilatation of the pulmonary arteries. These aneurysmal vessels can compress the tracheobronchial tree, causing respiratory distress [6]. Our patient was diagnosed at age of 21 years without signs of bronchial compression. He underwent surgery at 22 years old. Saygi reported a case of a woman diagnosed at 30 years old with respiratory symptoms caused by bronchial compression [7]. Diana reported, as in our case, a 16-year-old patient with no respiratory signs associated with bronchial compression [8]. Affangla also described a case of a 24-year-old patient who had been symptomatic since the age of 12 but had no major signs of bronchial compression [9].

The usual surgical treatment for bronchial compression consists of: bronchial decompression by plication of the pulmonary arteries associated or not with a 
LeCompte maneuver [10]. Reported techniques have included complete excision of the dilated PAs; a subtotal resection with flap augmentation and arteriopexy; an anterior or posterior resection with reduction of pulmonary arteries. The repair of pulmonary regurgitation and stenosis was done by a RV-PA valved conduit of homograft or heterograft tissue and the closure of the ventricular septal defect by a patch [3] [10]-[17].

The presence of a tracheobronchomalacia requires reinterventions for repeated plication of pulmonary arteries and, sometimes additional intrabronchial stenting [18]. In the series reported by Chen JM, the classical technique that consists in implantation of a homograft in pulmonary position, closure of the ventricular septal defect and pulmonary arterioplasty to release the bronchial compression was used [19].

Sachin Talwar in his retrospective study over a period of 10 years including 6 adults and 67 children; the dilatation of the pulmonary arteries was treated by the plication technique or the elliptical incision of the arterial wall; the ventricular septal defect was closed with a Dacron patch [20].

In our case, in the absence of signs of bronchial compression, we didn't make a plication of the pulmonary arteries. We opted for the implants using the bioprosthesis because of the age of the patient and the possibility of percutaneous dilatation of the valve or placement of the Melody type valves if any stenosis occurs at follow-up. The pulmonary regurgitation and stenosis were treated by infundibular fibromuscular resection and placement of a transannular hood patch on the trunk of the pulmonary artery after a bioprosthesis implantation. In the case reported by Diana E. et al. the patient also benefited from a transannular reconstruction and implantation of a $27 \mathrm{~mm}$ bioprosthesis pulmonary valve. The plication of the pulmonary arteries was not performed despite their aneurysmal dilatation [8]. There is less agreement, however concerning the method of RVOT reconstruction. Some centers have advocated utilization of either a valved homograft conduit or use of a transannular patch incorporating a monocusp valve [7] [21]. J.N Roan et al presented a surgical correction using a homemade bicuspid equine pericardial tube for right ventricular outflow reconstruction. The short-term follow-up demonstrated good motility of the pericardial leaflet. However, patients receiving this type of valved conduit require meticulous longterm follow-up [2]. There is no consensus exists about the preferred method of RV-PA reconstruction. Some authors have suggested that pulmonary valve competence is important in reducing long-term risk of arrhythmias and late RV dysfunction along with improving early postoperative hemodynamics and reduction of persistent PA dilatation (3, 5, and 22)

Sachin Talwar report an early mortality of $7.7 \%$ in children and no short- and medium-term mortality in patients operated in adulthood [22].

The most common complications in the series reported by Mathew S. Yong were pleural and pericardial effusions and complete AV bloc requiring a permanent pacemaker implantation [23]. Our patient only had mild pericardial effu- 
sion in the post-operative period.

\section{Conclusion}

The prognosis of Tetralogy of Fallot with agenesis of the pulmonary valves depends essentially on the existence or not of a bronchial compression by aneurismal dilatation of the pulmonary artery branches. Children generally show signs of bronchial compression which often imposes an urgent surgical intervention. Only few forms without major signs of bronchial compression can survive without surgical repair until adulthood. The surgical management of this condition requires several techniques of repair in addition to the classic treatment of Tetralogy of Fallot.

\section{Conflicts of Interest}

The author declares no conflicts of interest regarding the publication of this paper.

\section{References}

[1] Desai, D.B., Mathur, N.P. and Marik, A. (2020) Fallot Type of Absent Pulmonary Valve Syndrome. A Case Report. Indian Journal of Radiology and Imaging, 30, 240 243. https://doi.org/10.4103/ijri.IJRI $508 \quad 19$

[2] Roan, J.N., et al. (2006) Correction of Tetralogy of Fallot with Absent Pulmonary Valve Syndrome in a Young Infant Using a Bicuspid Equine Pericardial Tube, Case Report. Journal of the Formosan Medical Association, 105, 329-333. https://doi.org/10.1016/S0929-6646(09)60124-8

[3] Ilbawi, M.N., Idriss, F.S., Muster, A.J., Wessel, H.U., Paul, M.H. and DeLeon, S.Y. (1981) Tetralogy of Fallot with Absent Pulmonary Valve. Should Valve Insertion Be Part of the Intracardiac Repair? The Journal of Thoracic and Cardiovascular Surgery, 81, 906-915. https://doi.org/10.1016/S0022-5223(19)39426-7

[4] Mammen, V., Adams, P., Ntsinjana, H. and Cilliers, A. (2018) Tetralogy of Fallot with Absent Pulmonary Valve Syndrome: A 34 Year African Single Centre Experience. SA Heart Journal of the South African Heart Association, 15, 128-132. https://doi.org/10.24170/15-2-3046

[5] Alsoufi, B., Williams, W.G., Hua, Z., Cai, S., Karamlou, T., Chan, C.C., et al. (2007) Surgical Outcomes in the Treatment of Patients with Tetralogy of Fallot and Absent Pulmonary Valve. European Journal of Cardio- Thoracic Surgery, 31, 354-359. https://doi.org/10.1016/j.ejcts.2006.12.001

[6] Muhammad, Y.Q., Harold, M.B., Paul, J. and Frank, C. (2014) Importance of Absent Ductus Arteriosus in Tetralogy of Fallot with Absent Pulmonary Valve Syndrome. Texas Heart Institute Journal, 41, 664-667. https://doi.org/10.14503/THIJ-13-3674

[7] Saygi, M., Haydin, S., Guzeltas, A., Odemis, E. and Yeniterzi, M. (2014) A Rare Congenital Cardiac Anomaly in Adulthood: Tetralogy of Fallot with Absent Pulmonary Valve Syndrome. World Journal for Pediatric and Congenital Heart Surgery, 5, 330-333. https://doi.org/10.1177/2150135113513477

[8] Drogalis-Kim, D.E., Reemtsen, B.L. and Reardon, L.C. (2016) Unrepaired Tetralogy of Fallot with Absent Pulmonary Valve in a Mildly Symptomatic 16-Year-Old Boy. Texas Heart Institute Journal, 43, 517-519. https://doi.org/10.14503/THIJ-15-5385 
[9] Alain, A.D., et al. (2014) Agénésie de la valve pulmonaire: A propos d'un cas chez une sénégalaise de 24 ans. Pan African Medical Journal, 18, 76. https://doi.org/10.11604/pamj.2014.18.76.3250

[10] Rego, H., Jacinto, T., Araújo, A., Teixeira, A., Becasis, M. and Anjos, R. (2014) Tetralogia de Fallot com agenesia da válvula pulmonar. Revista Portuguesa de Cardiologia, 33, 391-392. https://doi.org/10.1016/j.repc.2014.01.009

[11] Hew, C.C., Daebritz, S.H., Zurakowski, D., del Nido, P.I., Mayer Jr., J.E. and Jonas, R.A. (2002) Valved Homograft Replacement of Aneurysmal Pulmonary Arteries for Severely Symptomatic Absent Pulmonary Valve Syndrome. The Annals of Thoracic Surgery, 73, 1778-1785. https://doi.org/10.1016/S0003-4975(02)03511-7

[12] Nolke, L., Azakie, A., Anagnostopoulos, P.V., Alphonso, N. and Karl, T.R. (2006) The Lecompte Maneuver for Relief of Airway Compression in Absent Pulmonary Valve Syndrome. The Annals of Thoracic Surgery, 81, 1802-1807. https://doi.org/10.1016/j.athoracsur.2005.12.001

[13] Hraska, V. (2005) Repair of Tetralogy of Fallot with Absent Pulmonary Valve Using a New Approach. Seminars in Thoracic and Cardiovascular Surgery. Pediatric Cardiac Surgery Annual, 1, 132-134. https://doi.org/10.1053/j.pcsu.2005.01.006

[14] Kirshbom, P.M., Jaggers, J.J. and Ungerleider, R.M. (1999) Tetralogy of Fallot with Absent Pulmonary Valve: Simplified Technique for Homograft Repair. The Journal of Thoracic and Cardiovascular Surgery, 118, 1125-1127. https://doi.org/10.1016/S0022-5223(99)70116-9

[15] Kreutzer, C., Schlichter, A. and Kreutzer, G. (1999) Tetralogy of Fallot with Absent Pulmonary Valve: A Surgical Technique for Complete Repair. The Journal of Thoracic and Cardiovascular Surgery, 117, 192-194. https://doi.org/10.1016/S0022-5223(99)70488-5

[16] Conte, S., Serraf, A., Godart, F., et al. (1997) Technique to Repair Tetralogy of Fallot with Absent Pulmonary Valve. The Annals of Thoracic Surgery, 63, 1489-1491. https://doi.org/10.1016/S0003-4975(97)00327-5

[17] Yang, J.H., Jun, T.G., Park, P.W., et al. (2008) Factors Related to the Durability of a Homograft Monocusp Valve Inserted during Repair of Tetralogy of Fallot as Based on the Mid- to Long-Term Outcomes. Cardiology in the Young, 18, 141-146. https://doi.org/10.1017/S1047951108001923

[18] Haute Autorité de Santé, Protocole national de diagnostic et de soins (2008) Cardiopathies congénitales complexes: Tétralogie de Fallot. Enegal. Haute Autorité de Santé.

[19] Chen, J.M., Glickstein, J.S., Margossian, R., et al. (2006) Superior Outcomes for Repair in Infants and Neonates with Tetralogy of Fallot with Absent Pulmonary Valve Syndrome. The Journal of Thoracic and Cardiovascular Surgery, 132, 1099-1104. https://doi.org/10.1016/j.jtcvs.2006.05.049

[20] Talwar, S., et al. (2017) Mid-Term Results of Correction of Tetralogy of Fallot with Absent Pulmonary Valve. Indian Heart Journal, 69, 767-771.

https://doi.org/10.1016/j.ihj.2017.04.009

[21] Jonas, R.A. (2016) Surgical Management of Absent Pulmonary Valve Syndrome. World Journal for Pediatric and Congenital Heart Surgery, 7, 600-604. https://doi.org/10.1177/2150135116651838

[22] Brown, J.W., Ruzmetov, M., Vijay, P., Rodefeld, M.D. and Turrentine, M.W. (2006) Surgical Treatment of Absent Pulmonary Valve Syndrome Associated with Bronchial Obstruction. The Annals of Thoracic Surgery, 82, 2221-2226.

https://doi.org/10.1016/j.athoracsur.2006.07.022 
[23] Yong, M.S., Yim, D., Brizard, C.P., et al. (2014) Long-Term Outcomes of Patients with Absent Pulmonary Valve Syndrome: 38 Years of Experience. The Annals of Thoracic Surgery, 97, 1671-1677. https://doi.org/10.1016/j.athoracsur.2014.01.035 